\title{
EUTANÁSIA E A TÉCNICA DE PONDERAÇÃO DE INTERESSE
}

\author{
EUTHANASIA AND THE TECHNIQUE OF CONSIDERATION OF \\ INTERESTS
}

\author{
Mônica de Oliveira Câmara ${ }^{1}$
}

\section{RESUMO}

O presente resumo tem por objeto a análise da autonomia privada em questões relacionadas à eutanásia, especialmente no que se refere ao consentimento dos pais para a realização do procedimento em filhos que ainda não atingiram a maioridade, questionando se é possível limitar o exercício dessa autonomia para decidir sobre o destino da prole incapaz. Através deste estudo é possível estabelecer a presença de dois direitos fundamentais supostamente em colisão, quais sejam o direito à vida e a liberdade individual, razão pela qual será apresentado a técnica de ponderação de interesses com base nas lições de Robert Alexy. É importante ressaltar a pertinência temática, pelo fato de que o Poder Judiciário, não só do Brasil como também de outros países, com frequência julga casos em que não se vislumbra o exercício da autonomia privada do próprio paciente-incapaz. No lugar dele coloca-se a manifestação de vontade dos genitores em pôr fim à vida do filho diante do sofrimento observado, tudo isso sob o manto da proteção do poder familiar. Para a realização deste resumo utilizou-se da pesquisa bibliográfica, buscando de início a análise da bioética, seu conceito e princípios, a fim de situar essa disciplina com o instituto da eutanásia, estabelecendo a correlação dos princípios bioéticos com o tema. Também tornou-se necessário estabelecer distinções entre os termos eutanásia, distanásia, ortotanásia, suicídio assistido e mistanásia, visando com isso delimitar com maior precisão o objeto de estudo. Em seguida, descreveu-se entendimento sobre a autonomia privada no ordenamento jurídico brasileiro, estabelecendo sua relação com o princípio da dignidade da pessoa humana. A análise do tema demonstrou ser igualmente relevante o estudo dos métodos pelos quais o intérprete deve utilizar para decidir se a autonomia privada deve ou não ser limitada, demonstrando a técnica da ponderação com base na teoria externa, distinguindo regras e princípios, segundo a doutrina de Robert Alexy. Por fim, afirma-se conclusivamente, que a atividade de decidir sobre a restrição a direitos fundamentais nos casos em que se discute a eutanásia deve ser realizada com um ônus argumentativo rigoroso, uma vez que em situações como as que foram objeto de estudo dificilmente é possível se utilizar do método de subsunção do fato à norma.

Palavras-chaves: Eutanásia. Autonomia. Ponderação de interesses.

\begin{abstract}
The purpose of this abstract is to analyze private autonomy in matters related to euthanasia, especially regarding the consent of parents to perform the procedure in children who have not yet come of age, questioning whether it is possible to limit the exercise of this autonomy to parents. decide on the fate of the unable offspring. Through this study it is possible to establish the presence of two supposedly colliding fundamental rights, namely the right to life and individual freedom, which is why the interest-weighting technique based on the lessons of Robert Alexy will be presented. It is important to highlight the thematic relevance, given that the Judiciary, not only in

1 Mestre em Direito Público e Evolução Social pela Universidade Estácio de Sá- UNESA, linha de pesquisa Direitos Fundamentais e Novos Direitos. Pós Graduada em Direito Civil e Processo Civil pela Universidade Gama Filho. Graduada pela Universidade do Grande Rio. Pesquisadora do Grupo de Pesquisa Reprodução Humana Assistida, Família, Transformação Social da Universidade do Grande Rio. Professora de Direito Civil da Universidade do Grande Rio. Coordenadora Adjunta do Núcleo de Prática Jurídica da Universidade do Grande Rio. Advogada.
\end{abstract}


Brazil but also in other countries, often judges cases in which the exercise of private autonomy of the incapable patient is not envisioned. In his place is placed the parent's manifestation of willingness to end the child's life in the face of observed suffering, all under the cloak of family power protection. For the accomplishment of this abstract we used the bibliographical research, seeking at first the analysis of bioethics, its concept and principles, in order to situate this discipline with the euthanasia institute, establishing the correlation of bioethical principles with the theme. It has also become necessary to distinguish between the terms euthanasia, dysthanasia, orthothanasia, assisted suicide and mystasia, in order to more precisely delimit the object of study. Then, an understanding of private autonomy in the Brazilian legal system was described, establishing its relationship with the principle of human dignity. The analysis of the subject proved to be equally relevant the study of the methods by which the interpreter should use to decide whether or not private autonomy should be limited, demonstrating the technique of weighting based on external theory, distinguishing rules and principles, according to the doctrine of Robert Alexy Finally, it is conclusively stated that the activity of deciding on the restriction of fundamental rights in cases in which euthanasia is discussed should be carried out with a rigorous argumentative burden, since in situations such as those which were the object of study it is hardly possible. possible from the fact subsumption method to the norm.

Keywords: Euthanasia. Autonomy. Weightingofinterests.

\section{INTRODUÇÃO}

O presente artigo tem como objeto de pesquisa a análise da colisão dos direitos fundamentais do direito à vida e da autonomia da vontade do paciente terminal incapaz diante da liberdade individual dos pais em decidir sobre adoção de procedimentos direcionados à prática da eutanásia. O principal objetivo do trabalho é analisar e estabelecer as técnicas para que o intérprete solucione a suposta colisão desses direitos necessitando demonstrar com clareza o caminho percorrido para se chegar ao resultado final.

O tema da eutanásia, assim como tantos outros ligados à bioética, está conectado com um direito fundamental primordial que é o direito à vida, mas também está atrelado ao direito de que ninguém deve ser submetido a um tratamento desumano cruel e degradante, em que há lados opostos, dois interesses conflitantes que têm como fundamentação comum o princípio da dignidade da pessoa humana, trazendo ao intérprete a tarefa de apresentar uma solução harmoniosa e justa.

O tema ganha maior complexidade diante do fato de que a eutanásia é praticada diante da autorização dos pais no exercício do poder familiar, restrigindo a autonomia existencial da criança e do adolescente sob a aparência do dever de proteção.

Faz-se necessário estabelecer que a autonomia dos indivíduos foi analisada considerando a autonomia privada, a par da autonomia pública, esta entendida como a possibilidade de todos os cidadãos participarem da vida pública.

Nesse contexto, a autonomia privada é aquela voltada para as liberdades públicas dos indivíduos, ou seja, aquela que confere a cada um o poder da autodeterminação, sendo, 
portanto, responsável pela condução da sua vida, de seus projetos ideais, sem a interferência de fatores externos.

No campo da bioética essa autonomia privada é melhor compreendida na microbioética, cujo objeto de estudo é a relação estabelecida entre médicos e pacientes, bem como a relação entre as instituições e os profissionais da área de saúde em geral.

Inicialmente, para atingir o objetivo dessa pesquisa, foi indispensável a análise da disciplina da bioética, estabelecendo seu conceito, evolução histórica e princípios aplicáveis a este campo do saber.

A bioética foi criada para facilitar a melhor compreensão dos impactos da evolução tecnológica na medicina, possibilitando maior interferência do homem nas questões atreladas ao início, à evolução e ao fim da vida.

O princípio da autonomia é um dos princípios basilares da bioética e de ser entendido como a necessidade dos médicos e demais profissionais da saúde respeitarem a vontade do paciente diante dos seus valores filosóficos, morais, religiosos e éticos.

Ao tratar da eutanásia, foi importante estabelecer algumas diferenças entre o instituto e seus conceitos correlatos, como a distanásia, ortotanásia, suicídio assistido e mistanásia. Além disso, fez-se mister a exposição de algumas questões relacionadas ao testatmento vital.

Em seguida, ressaltando a autonomia da vontade como princípio fundador da bioética, estabeleceu-se a relação entre a autonomia e o princípio da dignidade da pessoa humana, donde se pode concluir que muito embora a autonomia privada constitua um direito fundamental do indivíduo, inserida dentro do campo das liberdades, é possível que sofra restrições em hipóteses de igual importância.

Diante dessa limitação, inevitavelmente, enfrenta-se o problema da colisão de direitos fundamentais, razão pela qual o último tópico do presente artigo dedicar-se-á em analisar de que maneira as limitações da autonomia privada podem ser realizadas legitimamente.

Sob esse enfoque foi possível analisar a distinção entre regras e princípios, além da descrição da teoria interna e externa, segunda a doutrina de Robert Alexy.

Por meio dessa análise, pode ser observados que os direitos fundamentais ora se revestem como regras, ora como princípios, dependendo da situação individualmente considerada, cabendo dessa forma, ao intérprete fazer a ponderação sobre qual o interesse prevalecerá diante da colisão de direitos fundamentais devidamente assegurados pela Constituição da República Federativa do Brasil de 1988. 
Por fim, apresenta-se como conclusão do presente artigo a exigência do ônus argumentativo, recaindo sobre o intérprete, a legitimação dessa atuação, afastando-se qualquer arbitrariedade, porque a técnica de decisão mostra-se transparente.

\section{BIOÉTICA: CONCEITO, EVOLUÇÃO HISTÓRICA E PRINCÍPIOS}

Analisar a disciplina da Bioética significa trazer à baila o fenômeno da evolução tecnológica ocorrida no século XX, uma vez que esse período foi marcado por relevantes descobertas tecnológicas na área da medicina, em especial no que diz respeito às pesquisas com o DNA.

A possibilidade do homem intervir cada vez mais no seu desenvolvimento como ser humano passa a ser uma preocupação da comunidade científica, tendo em vista que a manipulação do material genético possibilitou a modificação do destino dos seres vivos. Nesse diapasão, os questionamentos sobre a clonagem humana, aspectos da reprodução humana assistida, a utilização das células-tronco como possibilidade de cura de doenças tornou-se constante no debate público, em nome do bem-estar.

Não se pode olvidar que esses avanços tecnológicos são fundamentais para garantir melhor qualidade de vida a todos, contudo não se pode deixar de mencionar que a manipulação inadequada dessas informações pode levar a destruição do próprio homem, não só por sua própria vontade, mas também pela atuação médica.

Em decorrência disso surgem objeções sobre os limites de atuação dos profissionais da saúde, até que ponto poderão eles intervir na vida humana. Essas indagações, levam naturalmente à necessidade em realizar uma leitura interdisciplinar para essa nova realidade, impondo um diálogo amplo, livre e democrático na comunidade científica em geral. Isso significa que profissionais de diversas áreas como a sociologia, o direito, a medicina, a psicologia, a economia, a teologia, devem participar das discussões sobre os temas que envolvam o impacto da tecnologia sobre a vida.

A partir dessas inquietações surge a Bioética como ciência que tem por finalidade estudar a atuação ética de todos os personagens envolvidos em temas que dizem respeito à preservação da vida humana. 
Heloisa Helena Barboza² menciona que o termo Bioética surgiu em 1971, quando o oncologista americano Van R. Potter referiu-se a expressão como uma nova disciplina, cujo objeto de estudo seria analisar os problemas éticos gerados pelos avanços nas ciências biológicas e médicas.

A disciplina surge como forma de estudar o desenvolvimento tecnológico, não somente por uma visão técnica, mas principalmente sob um enfoque humanista, envolvendo uma abordagem de valores morais no campo da ciência da vida.

Adriana Caldas de Rego Freitas Dabus Maluf ${ }^{3}$, ao tratar do conceito de Bioética, aponta que:

As diretrizes filosóficas dessa área começaram a consolidar-se após a tragédia do holocausto da Segunda Guerra Mundial, quando o mundo ocidental, chocado com as práticas abusivas de médicos nazistas, em nome da Ciência, cria um código para limitar os estudos relacionados.

Segundo a supracitada autora, a bioética exige um conhecimento de diversas ciências (biológica, médica, filosófica, jurídica) e seu objeto de estudo é descobrir as condições imprescindíveis para a utilização das inovações tecnológicas adotando uma conduta responsável para a preservação da vida humana, animal e do meio ambiente.

André Marcelo M. Soares e Walter Esteves Piñero ${ }^{4}$ destacam que a bioética passou por três importantes fases históricas. A primeira delas compreende o período de 1960 à 1977, momento em que surgem médicos e cientistas preocupados com as novas descobertas tecnológicas e científicas. A segunda etapa engloba os anos de 1978 à 1997, fase em que houve a publicação do relatório de Belmont, e ocorreu a primeira fertilização in vitro, e também processaram-se diversas descobertas na engenharia genética, criando a Associação européia de centros de ética médica, o Convênio Europeu de Biomedicina e Direitos Humanos, entre outros. A última fase diz respeito ao momento atual, iniciada em 1998, e que teve como marco inicial a descoberta do genoma humano, clonagem, aliado ao debate sobre a precariedade do sistema de saúde pública nos países em desenvolvimento.

Os autores descrevem, ainda, que a bioética pode ser analisada sob dois enfoques. O primeiro deles refere-se à liberdade individual, podendo ser chamada de microbioética, em que é possível analisar a relação entre médicos e pacientes, bem como a relação entre as

2 BARBOZA, Heloisa Helena. Os princípios da bioética e do biodireito. Revista Bioética, Rio de Janeiro, vol. 8, n. $\quad 2, \quad$ p. $\quad 209, \quad 2000 . \quad$ Disponível $\quad$ em: $<$ http://revistabioetica.cfm.org.br/index.php/revista_bioetica/article/view/276/275>. Acesso em 15 nov 2018.

3 MALUF, Adriana Caldas de Rego Freitas Dabus. Curso de bioética e biodireito. 3.ed. São Paulo: Atlas, 2015. p. 8.

4 SOARES, André Marcelo M; PIÑERO, Walter Esteves. Bioética e biodireito: uma introdução. São Paulo: Loyola, 2002. p.19. 
instituições e os profissionais de saúde em geral. E o segundo enfoque, que seria aquela em que se aponta a eficácia da disciplina no que tange ao bem comum, atribuindo os autores o nome de macrobioética, cujo objeto de estudo seria as questões relacionadas ao meio ambiente em busca da preservação da vida humana.

Nesse sentido, conforme mencionado, o presente artigo dedica-se a discutir a autonomia privada dos pacientes em pôr fim a sua própria vida, por encontrarem-se em estágio terminal, solicitando ao médico que lhes proporcione uma morte rápida, piedosa e sem dor. Portanto, cabe analisar aqui a bioética sob o primeiro aspecto descrito, qual seja, a microbioética.

Finalizando o presente tópico, tem-se adiante a análise dos princípios basilares da bioética. Heloisa Helena Barboza $^{5}$ descreve que os primeiros ensaios para estabelecer quais seriam os princípios norteadores da disciplina ocorreram durante o Congresso dos Estados Unidos em 1974, onde uma comissão ficaria responsável em delinear o tema. Aproximadamente quatro anos mais tarde, por meio do chamado Informe de Belmont, a comissão enumerou três princípios básicos, a saber: o princípio da autonomia, ou do respeito às pessoas por suas opiniões e escolhas, segundo valores e crenças pessoais; o da beneficência, que se traduz na obrigação de não causar dano e de extremar os benefícios e minimizar os riscos; o da justiça ou imparcialidade na distribuição dos riscos e dos benefícios, não podendo uma pessoa ser tratada de maneira distinta de outra, salvo haja entre ambas alguma diferença relevante.

Segunda a autora, mais tarde, Tom L. Beauchamp e James F. Childress incluíram um quarto princípio à bioética, o chamado princípio da não maleficência, consistente em impor ao médico um não fazer, evitando causar dano intencional ao paciente. Difere ele do princípio da beneficência pelo fato deste último tratar de uma ação positiva, prevenindo ou eliminando o dano, além de promover o bem, enquanto o princípio da não maleficência engloba uma ação negativa, um não agir para não causar danos ao indivíduo.

O princípio da beneficência traz como fundamento o fato de que os profissionais da saúde devem se utilizar de um tratamento que promova o bem do paciente, praticando ações que busquem sempre o benefício para o outro, agindo por um dever moral. A ideia trazida por este princípio é a de que o médico deve agir sempre visando evitar danos ao enfermo, maximizando os benefícios para ele. Esse princípio está eminentemente ligado aos pensamentos filosóficos de Kant. Isso porque, em sua obra Fundamentação da Metafísica dos

\footnotetext{
5 Ibidem, 2000, p. 211.
} 
Costumes $^{6}$, o filósofo alemão estabelece duas máximas, formando aquilo que ele designou por imperativo categórico. A primeira máxima consiste em o homem deve agir de tal maneira para que esta ação possa ser transformada em uma lei universal. A segunda máxima estabelece que o homem deve agir de tal maneira para que a humanidade do outro não seja um meio para justificar um fim, mas que a humanidade do outro seja um fim em si mesmo.

Essas duas máximas compõem o imperativo categórico, ou seja, quando o homem for agir o outro não deve ser usado para justificar o fim por ele pretendido. Kant afirma que as ações do homem para serem transformadas em leis universais não podem ser praticadas utilizando o outro como meio para justificar o fim almejado, mas que o outro deve ser um fim em si mesmo.

Uma ação só pode ser transformada em lei universal quando o outro é a preocupação, independentemente de quaisquer outros artifícios ou finalidades. Assim, os médicos e os demais profissionais da saúde devem sempre visar o bem-estar do paciente, evitando-lhe quaisquer danos.

O princípio da justiça exige dos profissionais da saúde o exercício do seu ofício distribuindo os riscos e benefícios de maneira imparcial, evitando qualquer discriminação.

O princípio da autonomia, por fim, valoriza a vontade do paciente, ou de seus representantes, levando em consideração seus valores morais e religiosos. Exige-se dos profissionais da saúde uma atuação transparente, informando aos indivíduos os riscos e benefícios que o procedimento médico proporcionará. A autonomia seria a capacidade de agir sem qualquer influência externa, consentindo ou não em ser submetido a determinado tratamento médico, mediante as informações recebidas. Desse princípio resulta a exigência do consentimento livre e informado.

\section{DIFERENÇAS ENTRE EUTANÁSIA, DISTANÁSIA, ORTOTANÁSIA, SUICÍDIO ASSISTIDO E MISTANÁSIA}

A eutanásia se destacou no conhecimento do homem do século $\mathrm{XX}$, por trazer questionamento de ética e moral diante dos avanços que a biotecnologia proporcionou ao campo da medicina, em especial aqueles que dizem respeito às inovações ligadas ao prolongamento da via.

6 KANT, Immanuel. Fundamentação da Metafísica dos Costumes. Coimbra: Atlântida, 1960, primeira seção, traduzida por Paulo Quintela, p. 15-33. 
O termo eutanásia, vem do grego e é composto de duas palavras, "eu", que significa boa, e "thanatos", que significa morte, podendo ser trazido como "boa morte".

No Brasil, a eutanásia não está regulamentada no ordenamento jurídico, sendo tratada como homicídio privilegiado, uma vez que o agente comete crime impelido por motivo de relevante valor moral, na medida em que sua intenção é diminuir o sofrimento do paciente que se encontra em estágio terminal, já que não há nenhuma chance de cura.

A eutanásia é o ato de antecipação da morte de um paciente em fase terminal, e que por se encontrar em constante sofrimento, acaba o enfermo optando, conscientemente em por termo a própria vida, solicitando uma morte rápida e sem dor. Exige-se do médico uma atitude ativa, na medida em que pode ele ministrar medicamentos que levam ao enfermo ao óbito, daí porque adota-se o nome de eutanásia ativa.

Já a distanásia é um método utilizado para prorrogar a vida do paciente a qualquer custo, utilizando medidas terapêuticas excessivas. É um tratamento desproporcional, submetendo o paciente a sofrimentos físicos e psicológicos desarrazoados.

A ortotanásia, também conhecida como eutanásia passiva, é o procedimento utilizado pelo médico diante de uma morte inevitável. Exige do profissional da medicina um não agir, deixando que a morte ocorra naturalmente. É o óbito do paciente ocorrendo em seu tempo adequado, não combatida com os métodos extraordinários e desproporcionais utilizados na distanásia, tampouco antecipado como na eutanásia ativa.O tratamento é interrompido no tempo certo, pois, do contrário, só haveria um prolongamento desnecessário do sofrimento e da agonia.

Importante destacar que a Resolução do Conselho Federal de Medicina n. o 1805/2006 permite ao médico limitar ou suspender procedimentos e tratamentos que prolonguem a vida do doente, garantindo-lhe os cuidados paliativos necessários para aliviar os sintomas que levam ao sofrimento., poupando-o de tratamento inútil ou doloroso, incovacando o artigo $5^{\circ}$, III da Constituição da República Federativa do Brasil de 1988, uma vez que ninguém deve ser submetido a tortura, nem a tratamento desumano ou degradante.

Oportuno lembrar, ainda, que a Resolução do Conselho Federal de Medicina n. ${ }^{\text {o }}$ 1995/2012, permite ao médico agir de acordo com a vontade do paciente, interrompendo o tratamento por sua solicitação, na medida em que estabelece as regras pertinentes ao testamento vital. Trata-se de um documento em que há uma declaração elaborada pelo próprio enfermo, expressando conscientemente quais são os tipos de tratamento que deseja ser submetido, a fim de que não tenha uma morte lenta e com sofrimento atroz. 
$\mathrm{O}$ artigo $1^{\circ}$ da citada resolução estabelece as chamadas diretivas antecipadas de vontade sendo um "conjunto de desejos, prévia e expressamente manifestados pelo paciente, sobre cuidados e tratamentos que quer, ou não, receber no momento em que estiver incapacitado de expressar livre e autonomamente, sua vontade"7.

Se o paciente não estiver em condições de exprimir sua própria vontade, o médico considerará suas diretivas antecipadas de vontades, analisando sua vida pregressa, sua própria manifestação feita algum parente ou amigo, devendo inclusive o profissional registrar em um prontuário a manifestação por ventura feita pelo próprio paciente durante a consulta médica (art. $2^{\circ}$ da Resolução CFM 1995/2012).

Suicídio assistido é a hipótese em que a retirada da própria vida ocorre com auxílio ou assistência de terceiro. $\mathrm{O}$ ato causador da morte é de autoria daquele que põe termo à própria vida. $\mathrm{O}$ terceiro colabora com o ato, quer prestando informações, quer colocando à disposição do paciente meios e condições necessárias à prática. No direito brasileiro, pune-se a conduta do agente que atua dessa maneira, haja vista que o induzimento e o auxílio ao suicídio tratamse de condutas típicas previstas no art. 122, do Código Penal.

Mistanásia é o termo utilizado para se referir à morte de pessoas que, excluídas socialmente, acabam morrendo sem qualquer ou com apenas uma precária assistência de saúde. Assim, pode-se afirmar que as vítimas da mistanásia são pessoas que não dispõem de condições financeiras para arcar com os custos advindos dos tratamentos da própria saúde, ficando na dependência da prestação de assistência pública.

Diante dessas distinções, é possível concluir que a eutanásia analisa de forma concomitante o direito à vida, garantido constitucionalmente no artigo $5^{\circ}$, caput, da $\mathrm{CRFB} / 88$, mas também passa pelo direito à morte digna, na medida em que ninguém deve ser submetido a qualquer tratamento, desumano, cruel e degradante, conforme estabelecido no mesmo artigo $5^{\circ}$, III, do diploma constitucional ainda que esse tratamento seja estabelecido por um profissional da saúde, sob o discurso de que a vida está acima de todos os outros direitos.

Desta feita, questiona-se sobre a inconstitucionalidade da eutanásia uma vez que poderia violar fatalmente o disposto no artigo $5^{\circ}$, caput da CRFB/88 que resguarda o direito à vida, mesmo que tenha por escopo atender ao princípio do respeito à dignidade humana (artigo $1^{\circ}$, III da Constituição) e ao da liberdade de autodeterminação ou de escolher entre a

\footnotetext{
7 Conselho Federal de $\quad$ Medicina, $\quad$ disponível $\quad$ em<
} http://www.portalmedico.org.br/resolucoes/cfm/2012/1995_2012.pdf > acesso em 30 nov 2018 
vida e a morte. Indaga-se: qual desses direitos deve prevalecer: o direito à vida ou o direito à liberdade?

Por envolver questões tão complexas, como o limite da autonomia do paciente e do médico, além de questões morais e religiosas, poucos países regulamentaram a prática da eutanásia.

A Colômbia, em 2015, por meio de um processo judicial a Corte Constitucional determinou que o Ministério da Saúde regulamentasse a eutanásia no país. Em março do corrente ano de 2018 possibilitou que o procedimento também fosse realizado em crianças acima de 6 anos de idade.

O Uruguai, apesar de não regulamentar a eutanásia, tem em seu artigo 37 do Código Penal a previsão do homicídio piedoso, podendo o juiz deixar de aplicar a pena se o agente praticar o crime imbuído de motivos de piedade, mediante súplicas reiteradas da vítima.

\section{A AUTONOMIA PRIVAdA SOB A ÓTICA DO PRINCÍPIO DA DIGNIDADE DA PESSOA HUMANA}

Comumente, o princípio da dignidade da pessoa humana é apresentado como fundamento em ambos os lados de uma demanda judicial quando são tratadas questões relativas ao aborto, suicídio assistido, utilização das células-tronco, o descarte dos embriões excedentários, entre outros temas correlatos.

Por essa razão, faz-se imprescindível a adoção de um conceito uniforme para que esse princípio possa ser útil na solução dos chamados casos difíceis, até mesmo como forma de evitar sua banalização.

Por casos difíceis entendem-se aquelas demandas em que não há uma solução prédeterminada pelo ordenamento jurídico. A resposta precisa ser construída pelo intérprete, uma vez que não há como estabelecer a subsunção do fato à norma, construção esta realizada em muitos casos à luz dos princípios.

Por outro lado, é preciso reconhecer também que o mundo contemporâneo ficou cada vez mais complexo, plural, sendo a escolha do que seja uma vida boa um critério adotado por cada um de acordo com seus valores morais, culturais e religiosos.

Além disso, normalmente, em temas relacionados à bioética as demandas envolvem questões em que não há um consenso, o que torna a solução complexa e sem a aplicabilidade de um critério objetivo. 
A dignidade da pessoa humana está na origem de todos os direitos fundamentais e fornece parte do conteúdo de cada um deles.

Segundo Luis Roberto Barroso $^{8}$, a dignidade da pessoa humana deve ser estudada de acordo com três conteúdos, a saber: valor intrínseco, autonomia e valor comunitário.

No plano filosófico, estabelece o citado jurista, que o valor intrínseco deve ser entendido como a possibilidade de identificar a pessoa humana no universo como ser especial, diferenciando-se das coisas e dos animais pelo fato do homem ser dotado de razão, do que se extrai dois postulados filosóficos importantes, a ótica anti-utilitarista e a visão anti-totalitária.

Isso significa dizer que, cada pessoa deve ser tratada de acordo com seus próprios propósitos, não podendo o direito de um indivíduo ser sacrificado em nome daquilo que for melhor para a maioria (visão anti-utilitarista). Além disso, deve o Estado ser visto como um meio para a promoção dos projetos dos indivíduos, atingindo cada um a sua própria felicidade (visão anti-totalitária).

No que se refere ao plano jurídico do valor intrínseco está a englobar o direito à vida, o direito á igualdade, o direito à integridade física e o direito à integridade moral.

Ainda seguindo as lições de Luis Roberto Barrosso, o segundo conteúdo do princípio da dignidade da pessoa humana, e este é o que mais interessa ao presente artigo, é a autonomia, ou seja, a capacidade de cada pessoa ter sua vontade respeitada, fazendo suas escolhas segundo suas valorações morais. Autonomia significa que cada indivíduo tem a liberdade de escolher as normas que regerão a sua conduta.

A autonomia resguarda um núcleo essencial de liberdade que deve está presente na vida de todos, incluindo neste conteúdo não só a autonomia privada, como também a autonomia pública.

Por autonomia privada entende-se um conjunto subjacente das liberdades públicas essenciais, como a liberdade de ir e vir, a liberdade de expressão, a liberdade religiosa e etc.

Pelo terceiro conteúdo do princípio da dignidade da pessoa humana, tem-se o valor comunitário, possibilitando situações em que a autonomia pode ser legitimamente limitada em nome de interesses do Estado e de interesses da sociedade.

Essa limitação ocorre em virtude de três motivações. A primeira delas é a limitação da autonomia do indivíduo para assegurar o direito de outrem. Se o exercício da autonomia da vontade violar os direitos fundamentais de outro indivíduo, deve ela ser limitada.

8 BARROSO, Luis Roberto. A Dignidade da pessoa humana no direito constitucional contemporâneo. Brasília, 10 abr. 201. Palestra proferida no UniCEUB (Centro Universitário de Brasília). Disponível em: < https://www.youtube.com/watch?v=MwaAsLs7kks>. Acesso em: 15 nov. 2018. 
A segunda motivação para o cerceamento da autonomia é a proteção da pessoa de si próprio. Quando o Estado proíbe o suicídio assistido, não atendendo a vontade e o desejo do paciente em por fim a sua vida diante do seu intenso sofrimento, está ele limitando a autonomia privada contra seu próprio ato (paciente).

A terceira motivação para a limitação da autonomia é a necessidade de imposição dos valores sociais. A pretensão aqui é estabelecer um valor moral, sobretudo quando existe um senso comum muito forte sobre a não aceitação de certa conduta.

O problema dessas limitações da autonomia privada é que corre o risco do Estado, sob o argumento de proteger, resolve intervir na vida dos indivíduos, impondo suas preocupações, sem que isso exista um consenso forte sobre o que é uma decisão correta, em especial quando se está diante de casos difíceis, como aqueles que dizem respeito à eutanásia.

Segundo as lições de Daniel Sarmento ${ }^{9}$, essas motivações à limitação da autonomia privada podem ser chamadas de intervenções heterônomas, no sentido de que uma ação de um indivíduo pode gerar impactos em toda a sociedade e não somente sobre a própria pessoa, havendo uma necessidade premente da existência de uma certa limitação desta autonomia para que se respeite a sociedade plural em que se vive, mantendo-se, dessa forma, a ordem coletiva.

Peter Singer ${ }^{10}$, ao escrever sobre questões ligadas ao aborto e a eutanásia, estabelece que não seria um erro o médico tirar a vida de alguém por sua própria solicitação, porque ao fazer esse pedido a pessoa estaria abrindo mão do direito à vida e portanto deve sua vontade ser respeitada. Afirma o autor que

O princípio do respeito pela autonomia afirma que devemos permitir que os agentes racionais vivam suas vidas de acordo com suas próprias decisões autônomas, livres de coerção ou interferência; mas, se os agentes racionais optarem autonomamente por morrer, o respeito pela autonomia nos deve levar a ajudá-los a pôr em prática sua opção.

No que se refere ao exercício da autonomia da criança e do adolescente entende-se que as decisões devem sempre ter como elemento norteador o melhor interesse do incapaz, o que está necessariamente vinculado à garantia do desenvolvimento da pessoa e, consequentemente, ao respeito da sua dignidade e autonomia. Assim, o conteúdo do melhor interesse não coincidirá, necessariamente, com a vontade do Estado, dos pais ou mesmo da própria criança/adolescente, devendo ser avaliado diante da situação concreta.

\footnotetext{
9 SARMENTO, Daniel. O princípio da dignidade da pessoa humana. Brasília, 02 jun. 2015. Palestra proferida na reunião do CBEC (Centro Brasileiro de Estudos Constitucionais). Disponível em: < https://www.youtube.com/watch?v=wy1EV5FA4HU>, Acesso em: 17 de nov. 2018.

10 SINGER, Peter. Ética Prática. 4 ed. São Paulo: Martins Fontes, 2018, p. 258-259.
} 


\section{COLISÃO DE DIREITOS FUNDAMENTAIS NO EXERCÍCIO DA AUTONOMIA PRIVADA}

Em primeiro lugar, insta salientar que não existe uma solução objetiva quando se está diante de um aparente conflito de direitos fundamentais envolvendo a eutanásia. É possível que haja uma resposta possível para determinado caso concreto, mas nem sempre poderá ser aplicada a outro caso da mesma maneira.

É nesse contexto que se desenvolvem as discussões de temas relacionados à bioética, chegando-se ao Judiciário demandas que não possuem uma solução pré-estabelecida, única e uniforme, não podendo ser utilizado simplesmente o tradicional método de subsunção do fato à norma. Indaga-se, portanto, qual é o método que o intérprete deve utilizar para que a restrição a um direito fundamental seja legitimamente considerada?

Segundo Jorge Reis Novais ${ }^{11}$, o conceito dessa restrição deve ser visto como qualquer ação ou omissão do Estado no sentido de trazer desvantagens para um direito fundamental em análise.

Virgílio Afonso da Silva ${ }^{12}$, analisando os ensinamentos de Robert Alexy sobre a teoria interna e externa dos direitos fundamentais, aponta que é preciso fazer a distinção das normas que enunciam direitos fundamentais entre regras e princípios.

Segundo ele, "se um direito é garantido por uma norma que tenha a estrutura de uma regra, esse direito é definitivo e deverá ser realizado totalmente, caso a regra seja aplicável ao caso concreto". A ideia delineada na regra é a aplicação da lógica do tudo ou nada.

Quanto aos princípios, esses devem ser considerados como mandamentos de otimização, pois exigem que algo seja realizado na maior medida possível diante das possibilidades fáticas e jurídicas existentes. Os princípios podem ser realizados em diversos graus. Esse grau de realização somente pode ocorrer se as condições fáticas e jurídicas forem ideais, o que dificilmente ocorre nos casos difíceis. Raramente a realização total de um princípio não encontrará barreiras na proteção de outro princípio ou de outros princípios.

Robert Alexy ${ }^{13}$, analisando a teoria dos direitos fundamentais, esclarece que as regras devem ser estudadas segundo a teoria interna, e os princípios segundo a teoria externa.

11 NOVAIS, Jorge Reis. As restrições aos direitos fundamentais não expressamente autorizadas pela Constituição. 2.ed. Coimbra: Coimbra, 2010.

12 SILVA, Virgílio Afonso. O conteúdo essencial dos direitos fundamentais e a eficácia das normas constitucionais. Revista de Direito do Estado, Ano 1, n. ${ }^{\circ}$ 4, p. 24. 
De acordo com a teoria interna, os direitos fundamentais são definidos sem levar em consideração fatores externos. Só há uma coisa: o direito com sua restrição, ou seja, a restrição ao direito fundamental já nasce dentro do próprio direito (limites imanentes). Fatores de origens externas, como é o caso das restrições decorrentes da colisão entre princípios, são sempre excluídos.

Já na teoria externa, o supracitado jurista, estabelece que a norma que elenca um direito fundamental, faz a distinção entre aquilo que está sendo protegido e as restrições, ou seja, as restrições estariam fora do âmbito de proteção da norma. O direito em si é, prima facie, um direito ilimitado que, a depender das particularidades do caso concreto, será limitado pelas restrições que, repita-se, lhe são extrínsecas.

Segundo os ensinamentos de Robert Alexy, as restrições aos direitos fundamentais devem ser realizadas adotando o método da proporcionalidade, onde nele existem três subprincípios: necessidade, adequação e proporcionalidade em sentido estrito.

Por necessidade deve-se perquirir se existe outra medida capaz de afastar a restrição, permitindo o exercício ilimitado do direito fundamental. Por adequação entende-se a capacidade do intérprete analisar se a medida restritiva é razoável ou se está ultrapassando aos limites legítimos da intervenção. Por proporcionalidade em sentido estrito está a aplicação do método de ponderação, sopesamento, consistente em analisar sobre qual direito deve prevalecer para satisfazer o valor axiológico da dignidade da pessoa humana.

Esse é o exercício que o intérprete deve fazer ao determinar a restrição de um direito fundamental: analisá-lo inicialmente como um direito ilimitado, mas que em um dado momento poderá sofrer restrições, não somente porque pode estar havendo uma violação ao direito fundamental de outra pessoa, mas também porque essa restrição poderá violar um direito fundamental do próprio indivíduo, como é o caso da eutanásia, em que o paciente tem o direito em não ser submetido a um tratamento médico que prolongue sua vida, com sofrimento, de forma desumana, cruel e degradante.

Assim, vale ressaltar que nem sempre um direito fundamental pode ser classificado aprioristicamente como regra ou princípio, é preciso analisar de forma individualizada, conforme o modo de aplicação da norma: se no modelo tudo ou nada ou se resultado de uma atividade de ponderação.

13 ALEXY, Robert. Teoria de los derechos fundamentales. Madrid: Centro de EstudiosPoliticos y Constitucionales, 2002. 
Já que a norma jurídica que traz os direitos fundamentais não é capaz de prever todas as soluções para os fatos da vida, daí porque apresenta-se como cláusulas abertas, não é possível a utilização do método de subsunção, porque a resposta aos problemas enfrentados não está integralmente no sistema jurídico.

Luis Roberto Barroso ${ }^{14}$ ensina que:

As denominadas cláusulas gerais ou conceitos jurídicos indeterminados contem termos e expressões de textura aberta, dotados de plasticidade, que fornecem um início de significação a ser complementado pelo intérprete, levando em conta as circunstâncias do caso concreto.

Nessa atividade de ponderação dos direitos fundamentais exige-se do julgador, um ônus argumentativo maior, cabendo ao intérprete uma atividade de coparticipação, aproximando o direito a outras ciências. Um exercício dialógico com diversos atores sociais, buscando assim dar concretude ao valor axiológico do ordenamento jurídico brasileiro, qual seja: proporcionar a pessoa humana uma vida digna.

No que diz respeito aos casos em que envolvam a eutanásia essa exigência de fundamentação das decisões é imprescindível para uma melhor resposta a ser dada pelo Poder Judiciário, cujo o papel tem sido cada vez maior em questões polêmicas e relevantes para a sociedade.

Daniel Sarmento ${ }^{15}$ descreve que a nova visão da normas constitucionais, permitindo que elas se irradiem para todo o ordenamento jurídico, fase que este o autor chama de neoconstitucionalismo, impõe a criação de novos métodos de argumentação que possibilitam construir um raciocínio coerente diante da incapacidade das normas jurídicas de prever todas as situações fáticas que podem se desenvolver na vida dos cidadãos.

O ideal é que cada pessoa tenha o direito de escolher como deseja exercer seu projeto de vida, não tendo o Estado o direito de fazer essa escolha no lugar de cada indivíduo, mas quando assim realiza que desenvolva uma atividade lógica, coerente, com fundamentação racional, capaz de fazer com que todos sejam capazes de entender que a solução encontrada foi a que melhor atende aos anseios sociais, pacificando a ordem da coletividade.

14 BARROSO, Luis Roberto. Neoconstitucionalismo e constitucionalização do direito: o triunfo tardio do direito constitucional brasileiro no Brasil. Revista de Direito Administrativo, Rio de Janeiro, v. 240, p. 142, 2005. Disponível em: < http://bibliotecadigital.fgv.br/ojs/index.php/rda/article/view/43618/44695>. Acesso em: 15 nov. 2018.

15 SARMENTO, Daniel. O neoconstitucionalismo no Brasil: riscos e possibilidades. Revista Brasileira de Estudos Constitucionais, Belo Horizonte, v. 3, n. 9, jan. 2009. Disponível em: <http://bdjur.stj.jus.br/dspace/handle/2011/29044>. Acesso em: 15 nov. 2018. 
No que diz respeito ao reconhecimento da autonomia da criança e do adolescente diante da incerteza sobre o seu discernimento, Thaís Seco ${ }^{16}$ apresenta alguns critérios que as decisões devem se pautar, quais sejam: a (ir)reversebilidade e (in)adiabilidade.

Segundo a autora, as decisões com caráter irreversível e adiáveis devem ser postergadas, enquanto que as decisões reversíveis e inadiáveis devem ser adotadas no momento correto ou imediatamente, impondo à família e ao Estado um agir. Quanto às decisões revestidas do caráter reversível e adiáveis, as quais representam um baixo ônus para a família e para o próprio infante, o ideal seria deixar para a própria interação social-afetiva ser o parâmetro para a solução do caso concreto. A maior dificuldade está nas decisões irreversíveis e inadiáveis, onde aí se inclui o tema relacionado à eutanásia, devendo antes de qualquer atitude a ser tomada direcionar a análise do caso concreto para uma equipe multidisciplinar, composta por profissionais habilitados em outras áreas, como a psicologia e a medicina, a fim de se alcançar a solução mais adequada a promover a dignidade da criança e do adolescente.

\section{CONSIDERAÇÕES FINAIS}

A bioética, como se pode observar, foi uma disciplina criada para estudar mais detalhadamente os impactos que a evolução tecnológica causou na medicina, permitindo que o homem cada vez mais interfira no seu próprio destino, criando novas relações jurídicas nunca antes imaginadas pelo legislador.

Por outro lado a exigência de se garantir a todos uma vida digna, colocando a pessoa humana como centro de todo o ordenamento jurídico, proporciona com que a vontade do indivíduo seja sempre relevante para criar o projeto de vida capaz de garantir a sua felicidade.

Ocorre que nem sempre poderá a pessoa humana exercer ilimitadamente sua vontade, porque a par dela está a necessidade de proteção de outros indivíduos e também da própria pessoa.

Nesse cenário é comum que surjam interesses conflitantes na busca da garantia de direitos fundamentais, os quais estão elencados na Constituição como cláusulas abertas e com conceitos jurídicos indeterminados, até para que o intérprete possa sempre aplicá-los de acordo com as modificações ocorridas em um dado momento histórico, impondo novas interpretações sempre que assim exigir os anseios sociais.

16 SECO, Thaís. Por uma nova hermenêutica do direito da criança e do adolescente. Civilistica.com, Rio de Janeiro, v.3, n.2, p. 18, ago/dez, 2014. 
Nessa atividade de interpretação surgiram novos métodos de argumentação que auxiliam ao intérprete a proferir uma adequada solução para os casos difíceis.

A teoria interna e externa, descrita por Roberta Alexy, é capaz de demonstrar com clareza as etapas de construção para estabelecer o interesse que deve prevalecer diante de um caso concreto, permitindo que os cidadãos possam melhor entender os motivos pelos quais se chegou a determinada conclusão.

Exige-se no supracitado critério decisório uma fundamentação maior diante de situações em que não é possível realizar o método da subsunção, sem significar com isso o afastamento da imposição constitucional da motivação das decisões em todos os casos que se deseja uma solução.

Nessa atividade decisória é possível haver a limitação aos direitos fundamentais que só se justificam quando estiver em jogo outro direito, que apesar de figurar no mesmo patamar hierárquico do ordenamento jurídico, goza de prioridade em relação a outro, em razão das peculiaridades do caso concreto. Essas restrições trazem consigo, portanto, a imposição de um ônus argumentativo ao intérprete para demonstrar não só sua legitimidade, mas também que não está havendo injustiça na violação a direito fundamental.

$\mathrm{O}$ estudo revela a dificuldade em seu determinar o que seria o direito à vida digna, cabendo ao intérprete construir a melhor solução para a hipótese apontada, tendo sempre como referência o valor da pessoa humana. Outra dificuldade analisada é o dilema em se estabelecer a capacidade de discernimento da criança e do adolescente em decidir sobre seu destino, o que interfere no exercício de sua autonomia.

Diante dos fatos, é possível formular algumas opiniões para o debate em torno do direito a uma vida digna. Na esteira da morte digna, deve-se considerar a expressa renúncia ao tratamento pela vontade do paciente consciente, capaz e devidamente informado das consequências de sua escolha, mesmo quando a renúncia possa resultar direta e indiretamente no término da vida. O paciente inconsciente ou se por algum outro motivo não puder expressar livremente seu desejo, poderá ter sua declaração anterior, aceitar o não atendimento de sua manifestação de vontade, apenas diante de transformações significativas na eficiência ou variedade dos tratamentos médicos disponíveis. Em se tratando de criança e adolescente deve as decisões adotar um critérios ainda mais rigorosos, diante do fato de que o exercício de sua autonomia está sendo realizado através de interposta pessoa, seus pais.

Todas essas questões envolvem a proteção de direitos fundamentais cabendo a discussão do tema na esfera social, evitando um choque improdutivo entre os extremos, com 
muitos preconceitos e nunca disposto ao consenso. A posição a ser assumida é de um debate democrático.

Nesse sentido, o direito positivo brasileiro ainda precisa de meios para contribuir para soluções constitucionalmente adequadas para os conflitos estudados.

Ainda que, o legislador não tenha se atentado para sua missão, cabe ao intérprete, seja pela declaração de inconstitucionalidade ou interpretação conforme a Constituição, implantar de maneira possível para que o direito à vida deixa o plano puramente estrutural e abstrato da forma que vem sendo tratado dos preceitos jurídicos com dogmas religiosos e morais, para que possa adentrar no plano objetivo e concreto da proteção de uma morte ou uma vida com dignidade a toda pessoa humana, conforme seus próprios desígnos.

\section{REFERÊNCIAS}

ALEXY, Robert. Teoria de losderechosfundamentales. Madrid: Centro de EstudiosPoliticos y Constitucionales, 2002.

HENRIQUES, Antonio; MEDEIROS, João Bosco. Metodologia científica na pesquisa jurídica. 9 ed. São Paulo: Atlas, 2017.

BARBOZA, Heloisa Helena. Os princípios da bioética e do biodireito. Revista Bioética, Rio de Janeiro, vol. 8, n. 2, p. 209-216, 2000. Disponível em: < http://revistabioetica.cfm.org.br/index.php/revista_bioetica/article/view/276/275>. Acesso em 15 nov 2018

BARROSO, Luis Roberto. A Dignidade da pessoa humana no direito constitucional contemporâneo. Brasília, 10 abr. 201. Palestra proferida no UniCEUB (Centro Universitário de Brasília). Disponível em: < https://www.youtube.com/watch?v=MwaAsLs7kks>. Acesso em: 15 nov. 2018. Administrativo, Rio de Janeiro, v. 240, p. 1-42, 2005. Disponível em: < http://bibliotecadigital.fgv.br/ojs/index.php/rda/article/view/43618/44695>. Acesso em: 15 nov. 2018.

BRASIL. Conselho Federal de Medicina. Resolução CFM n. 1995/2012, disponível em $<$ http//www.portalmedico.org.br/resolucoes/cfm/2012/1995_2012.pdf> acesso em 30 nov 2018.

MALUF, Adriana Caldas de Rego Freitas Dabus. Curso de bioética e biodireito. 3.ed. São Paulo: Atlas, 2015.

NOVAIS, Jorge Reis. As restrições aos direitos fundamentais não expressamente autorizadas pela Constituição. 2.ed.. Coimbra: Coimbra, 2010.

SARMENTO, Daniel. O neoconstitucionalismo no Brasil: riscos e possibilidades. Revista Brasileira de Estudos Constitucionais, Belo Horizonte, v. 3, n. 9, jan. 2009. Disponível em: <http://bdjur.stj.jus.br/dspace/handle/2011/29044>. Acesso em: 15 nov. 2018. 
O princípio da dignidade da pessoa humana. Brasília, 02 jun. 2015. Palestra proferida na reunião do CBEC (Centro Brasileiro de Estudos Constitucionais). Disponível em: < https://www.youtube.com/watch?v=wy1EV5FA4HU>, Acesso em: 17 de nov. 2018.

SECO, Thaís. Por uma nova hermenêutica do direito da criança e do adolescente. Civilistica.com, Rio de Janeiro, v.3, n.2, ago/dez, 2014.

SILVA, Virgílio Afonso. O conteúdo essencial dos direitos fundamentais e a eficácia das normas constitucionais. Revista de Direito do Estado, Ano 1, n. ${ }^{\circ} 4$.

SINGER, Peter. Ética Prática. 4 ed. São Paulo: Martins Fontes, 2018

SOARES, André Marcelo M; PIÑERO, Walter Esteves. Bioética e biodireito: uma introdução. São Paulo: Loyola, 2002. 